(REVIEW ARTICLE)

\title{
Retrohepatic vena cava lesion: which we cannot forget?
}

\author{
Melo e Silva Bruna Balbina 1, Dantas Elza Araújo 1, Arboés Henrique Eduardo Romão 1, Oliveira Larissa \\ Queiroz 1, Veras de Freitas Mayane Abrantes 1, Rêgo Amália Cinthia Meneses ${ }^{2}$ and Araújo-Filho Irami 3, * \\ ${ }^{1}$ UnP - Potiguar University - Laureate International Universities - Natal/Brazil. \\ 2 Postgraduate Program in Biotechnology at Potiguar University/UnP - Laureate International Universities - \\ Natal/Brazil. \\ ${ }^{3}$ Full Professor Department of Surgery, Federal University of Rio Grande do Norte. Postgraduate Program in \\ Biotechnology at Potiguar University/UnP - Laureate International Universities - Natal/Brazil.
}

Publication history: Received on 26 July 2019; revised on 06 August 2019; accepted on 09 August 2019

Article DOI: https://doi.org/10.30574/wjarr.2019.3.1.0047

\begin{abstract}
Vascular lesions are the leading cause of death after abdominal trauma. Among them, the inferior vena cava (IVC) lesion, especially its retrohepatic portion, is one of the most severe, rare, and complicated treatment. The difficult access and delicate anatomical relationships do not favor hemostasis. The etiology of the lesion is variable, resulting from penetrating trauma (transection and/or laceration), blunt or, more rarely, iatrogenic causes. After the initial approach of the polytraumatized patient, the identification of vascular damage must be early, so that surgical treatment of those patients presenting severe hypovolemic shock can be successful. Therapeutic options include tamponade of the lesion through adequate hepatic packaging, digital compression, or repair of the lesions after exposure of the retrohepatic area. In injuries that have not been controlled with tamponade, the total hepatic vascular exclusion is the treatment of choice. In extreme cases, the atriocaval shunt can be performed; however, compared with the vascular isolation technique, the latter showed a better survival rate. Besides, conservative treatment in selected cases of traumatic lesions of retrograde hepatic IVC is feasible and a priority because of the high mortality intrinsic to the surgical procedure. In this sense, the present review reinforces the need for continuous clinical and surgical improvement to obtain outcomes with a better prognosis, especially in retrohepatic vena cava lesions.
\end{abstract}

Keywords: Abdominal trauma; Inferior vena cava; Injury; Trauma; Wounds and injuries; Penetrating wounds

\section{Introduction}

Vascular lesion remains the leading cause of death after abdominal trauma [1,2]. Any patient with abdominal injury arriving in extremis should be considered as having an abdominal vascular injury. Vascular lesions are a common problem in urban trauma centers, occurring in 10 to $20 \%$ of all patients undergoing laparotomy for penetrating trauma in the urban civilian population [3].

Particularly dangerous, the most significant abdominal venous lesions have mortality between $50-90 \%$ and require a comprehensive knowledge of the various patterns of abdominal vascular injuries and the multiple operative strategies available. Factors such as the presence of shock at admission, comorbidities, visceral lesions, as well as a lesion in the inferior vena cava (IVC) are predictors of mortality and elevate morbidity [3].

Damage to the retrohepatic portion, although rare, is one of the most serious and challenging to manage, despite all improvements in technical skills and hospital care $[2,4]$. This type of lesion challenges the most experienced surgeons [5], both due to complicated access, anatomical relationships, and the difficulty of controlling bleeding in an area behind and tightly related to the liver [6].

\footnotetext{
${ }^{*}$ Corresponding author

E-mail address: irami.filho@uol.com.br
} 
The primary endpoint of IVC lesions is mortality. Secondary outcomes depend on variables related to the health system and the patient, such as time from trauma to first care, hospital conditions, technical skills of the surgical team, length of stay in the intensive care unit, complications during hospitalization and comorbidities [7]. Such factors will be determinant for the prognosis and evolution of the patient.

Most of the therapeutic indications from retrospective studies of reduced sample size, and even in the clinical protocols proposing technical solutions for the various types of lesions, the number of deaths is still significant [8].

Among the variables involved in conducting complex cases, the need for early recognition of the lesion and improvement of clinical and surgical management for an effective intervention has made the retrograde hepatic IVC lesion a challenge for all professionals working in trauma centers [7-9].

Considering such arguments and in the absence of a consensus on the best treatment for these severe lesions, the present study review conducts and rethink the current therapeutic approaches.

\section{Material and methods}

The studies were searched in the Pubmed, Scopus, Web of Science, Embase and Scielo databases, as well as the gray literature search through Google Scholar. The following MESH terms or descriptors/keywords were used: abdominal trauma, inferior vena cava, injury, trauma, wounds, and injuries, penetrating wounds, therapeutics, where articles were selected in English, Spanish and Portuguese. A total of 117 articles were identified, including 37 publications on the subject in the period between 1971 and 2019, in the categories of case reports, literature review, longitudinal retrospective study, cohort study, cross-sectional, randomized clinical trial, systematic review, and meta-analysis, when there was. The articles were selected in pairs, blindly, with a third author in case of conflict to decide whether the study would be included or not. The authors selected the articles by reading the title and abstract, including only those dealing specifically with vena cava lesions, in particular, retro-hepatic vena cava.

\section{Results and discussion}

\subsection{Anatomy}

The IVC begins anteriorly to the fifth lumbar vertebra by the union of the common iliac veins, to the right of the median plane, inferiorly to the bifurcation of the aorta and posterior to the proximal part of the common iliac artery. The IVC ascends to the right of the lumbar vertebral bodies, over the right psoas muscle, to the right of the aorta [10]. As it ascends, it receives numerous tributaries, including the right adrenal vein, the right and left renal veins, the right gonadal vein (testicular or ovarian), the third and fourth lumbar veins and the inferior phrenic veins. The left adrenal and gonadal vein drain indirectly to the IVC because they are tributaries of the left renal vein [11]. These tributaries correspond to the pair of visceral and parietal branches of the abdominal part of the aorta. The veins that correspond to the odd visceral branches of the aorta are tributaries of the portal vein, and the blood they carry enters the IVC through the hepatic veins in the retrohepatic portion below the diaphragm (Figure 1) [8].

VCI is a delicate, thin-walled vessel with a diameter of approximately $2.5-3.75 \mathrm{~cm}$, has a high flow and an intraluminal pressure of approximately $5 \mathrm{cmH}_{2} \mathrm{O}(3.67 \mathrm{mmHg})[9,10]$. It has no valves along its entire length, except for a variable, non-functional valve in an ostium located in the right atrium of the heart [8]. 


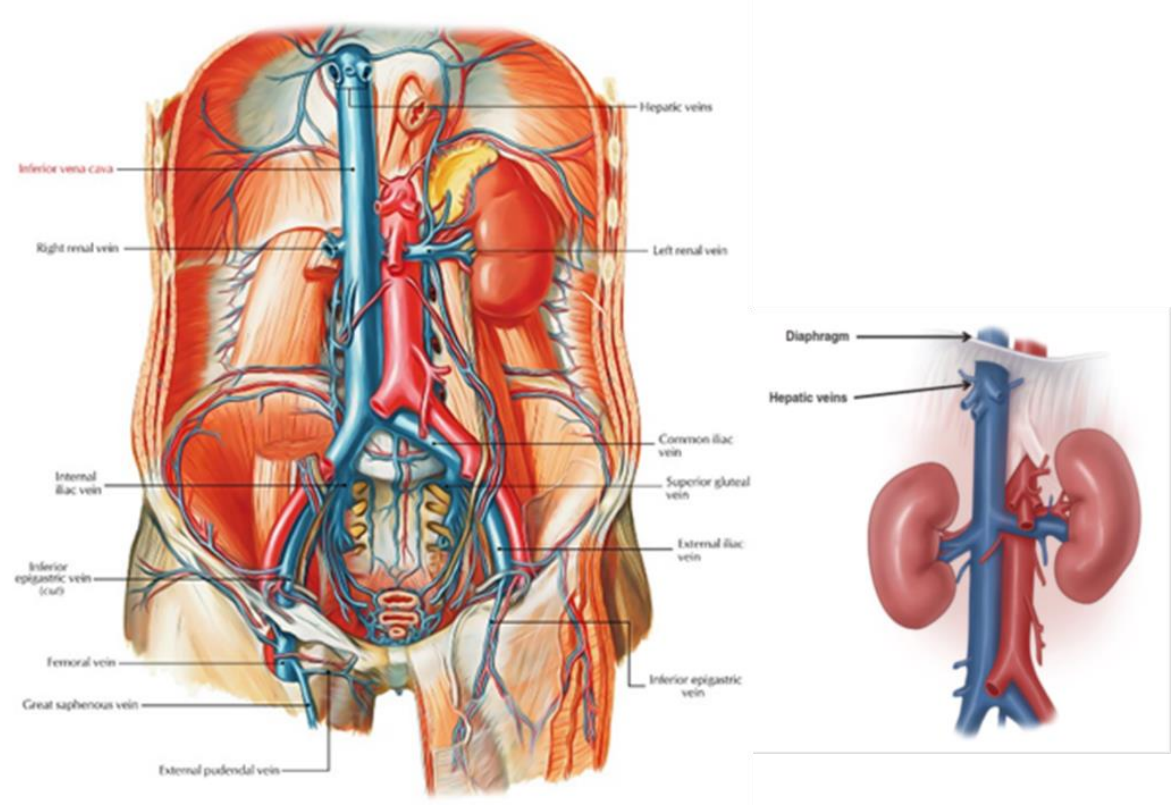

Figure 1 Vena cava inferior anatomy. 1A - Retroperitoneal view of the vena cava. 1B - Anatomical relationships between vena cava, abdominal aorta, kidneys, suprahepatic veins, and diaphragm.

Sources: A. https://www.earthslab.com/anatomy/inferior-vena-cava-ivc/ B. Cambridge Cambridge University Press. doi:10.1017/CBO9781107045156.032.

The IVC can be divided into five portions, each with anatomical peculiarities that affect surgical exposure and injury control in these locations: the lower section is the bifurcation, the infra-renal, perineal, adrenal/subhepatic and retrohepatic, the latter being the focus of the present study (Figure $2 \mathrm{~A} / \mathrm{B}$ ) [9-12].
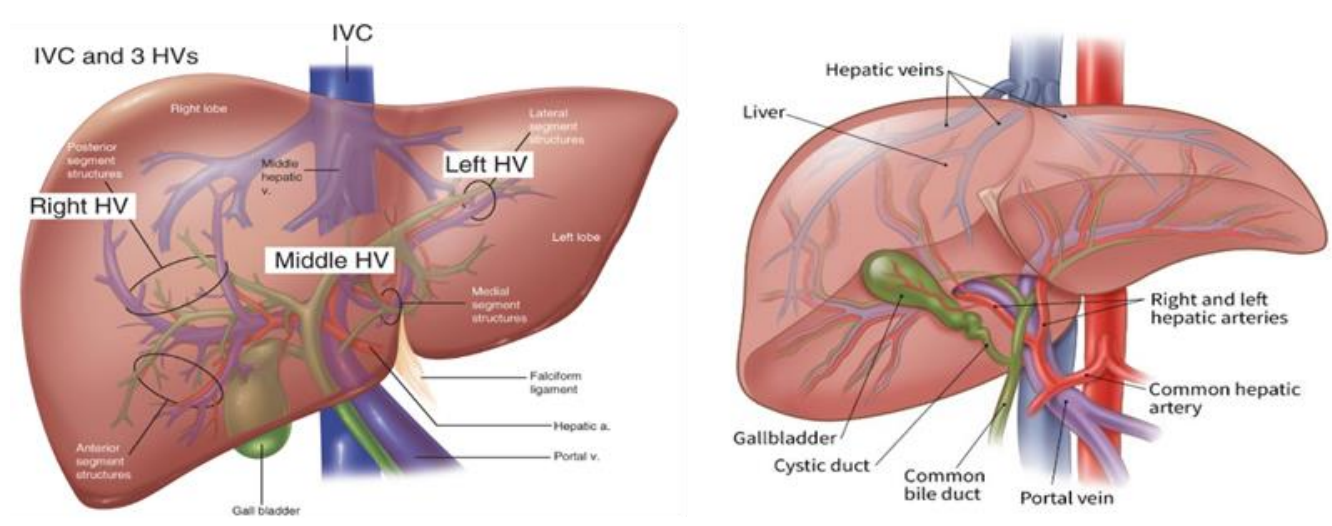

Figure 2 Retrohepatic vena cava anatomy. 2A - Diaphragmatic view of the liver and its three-dimensional anatomical relationships involving the vena cava, hepatic pedicle and its branches, biliary tree, and suprahepatic veins. 2B - View of the visceral face of the liver and its three-dimensional anatomical relationships involving the vena cava, the hepatic pedicle and its branches, the biliary tract, and the suprahepatic veins.

The segment of the retrohepatic IVC has peculiar anatomical characteristics. It is the portion of the IVC that is located superiorly to the right adrenal vein, inferior to the phrenic veins and in the posterior aspect of the liver, occupying a length of 7-10 cm. This area is entirely circumscribed by the hepatic suspensory ligaments, with the diaphragm posteriorly and the liver anterior $[12,13]$. The hepatic veins, formed by the union of the collecting veins that, in turn, drain the central veins of the hepatic parenchyma, flow into the retrohepatic segment, below the diaphragm. The fixation of these veins to the IVC helps maintain the liver in its anatomical position $[8,14]$ (Figure $3 \mathrm{~A} / \mathrm{B}$ ). 


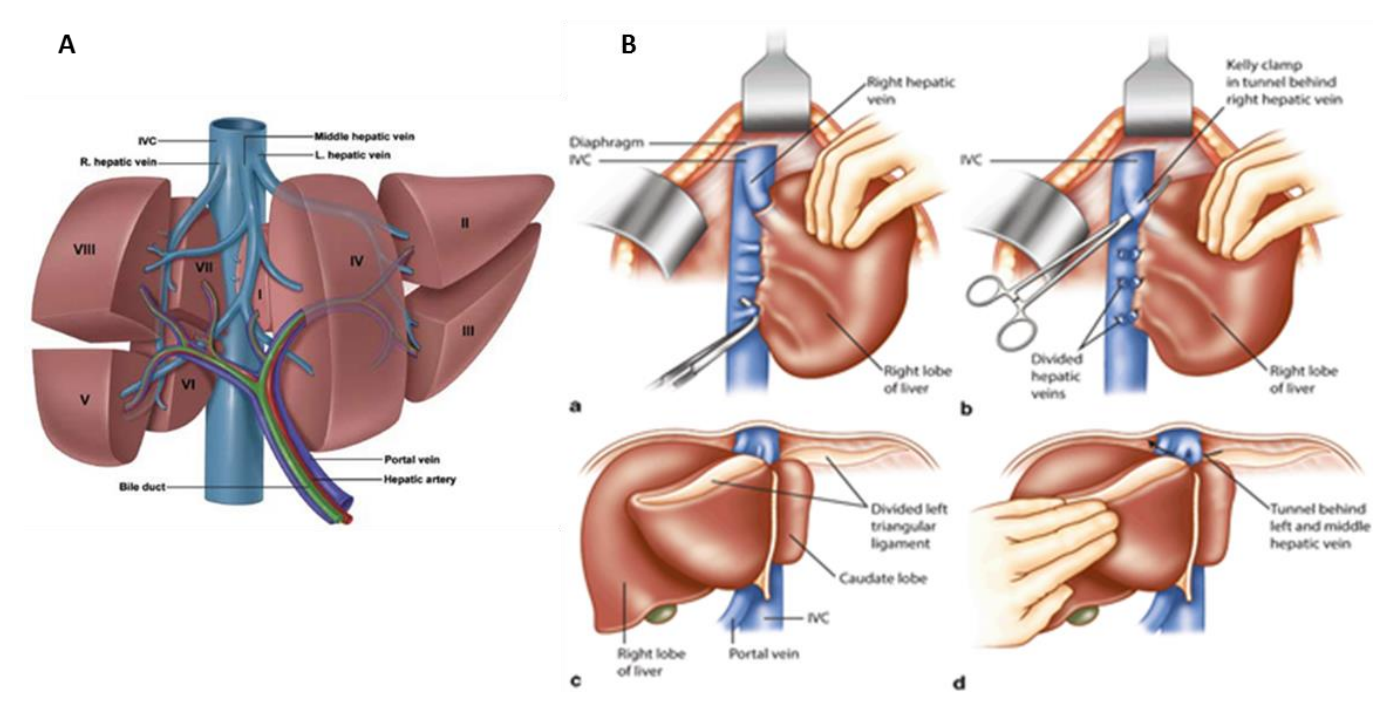

Figure 3A - Liver segmentation according to Couinaud; 3B - Retrohepatic vena cava access maneuvers. Sources: Hepatobiliary Surg Nutr 2014; 3 (3): 149-153. doi: 10.3978 / j.issn.2304-3881. https://link.springer.com/chapter/10.1007/978-1-4939-1200-1 10

\subsection{Epidemiology}

The IVC lesion is among the most frequent vascular lesions, with mortality around 33-66\% [12, 13]. Traumatic IVC lesions are associated with high morbidity and mortality rates. More than half of the patients are declared dead upon arrival at the hospital, and among those who arrive at the service with signs of life, mortality rates are very high [15].

Some factors contribute favorably or not to the patient's prognosis, such as the location of the lesion in the different segments of the cava vein $[2,7]$. The injuries of retrohepatic IVC and hepatic veins are the ones with the worst prognosis $[16,17]$. In a retrospective study performed by Maciel et al., It was observed that the lesions of retrohepatic IVC, although uncommon in the general context, were the most common among patients who died [7].

\subsection{Etiology}

The etiology of the retrohepatic IVC lesion is variable and in most cases presents as a penetrating lesion (transection and/or laceration). Almost every patient suffering from this type of injury has trauma to other viscera, large vessels, or both. Simultaneous lesions of the liver, duodenum, pancreas, intestine, and colon are common $[6,9,14,15]$.

Lesions may derive from a blunt mechanism. In these cases, they are caused by shearing forces in accidents of violent deceleration $[14,15]$.

Another type of involvement of the retrohepatic IVC is iatrogenic etiology, with high mortality, which requires rapid recognition and repair [5].

Hepatic lesions are classified by the American Association of Trauma Surgery (AAST), distributed in degrees from I to VI, varying from hematomas of reduced proportions to significant vascular lesions. The lesion of the retrohepatic IVC segment is defined as grade $\mathrm{V}$ by the AAST classification, as well as the vascular lesions related to the just hepatic veins (Table 1) [18]. 
Melo e Silva et al. / World Journal of Advanced Research and Reviews, 2019, 03(01), 001-011

Table 1 Grading of liver injury based on American Association of Surgery for trauma (AAST) ${ }^{19}$

\begin{tabular}{|c|c|c|}
\hline Grade & Type & Injury description \\
\hline \multirow[t]{2}{*}{ I } & Hematoma & Subcapsular, nonexpanding, $<10 \mathrm{~cm}$ surface area \\
\hline & Laceration & Capsular tear, nonbleeding, $<1 \mathrm{~cm}$ parenchymal depth \\
\hline \multirow[t]{2}{*}{ II } & Hematoma & $\begin{array}{l}\text { Subcapsular, nonexpanding, 10-50\% surface area; intraparenchymal nonexpanding }<10 \mathrm{~cm} \\
\text { diameter }\end{array}$ \\
\hline & Laceration & Capsular tear, active bleeding, $1-3 \mathrm{~cm}$ parenchymal depth $<10 \mathrm{~cm}$ in length \\
\hline \multirow[t]{2}{*}{ III } & Hematoma & $\begin{array}{l}\text { Subcapsular, }>50 \% \text { surface area or expanding; ruptured subcapsular hematoma with active } \\
\text { bleeding; intraparenchymal hematoma }>10 \mathrm{~cm} \text { or expanding }\end{array}$ \\
\hline & Laceration & $>3 \mathrm{~cm}$ parenchymal depth \\
\hline \multirow[t]{2}{*}{ IV } & Hematoma & Ruptured intraparenchymal hematoma with active bleeding \\
\hline & Laceration & $\begin{array}{l}\text { Parenchymal disruption involving } 25-75 \% \text { of hepatic lobe or one to three Couinaud's } \\
\text { segments within a single lobe }\end{array}$ \\
\hline \multirow[t]{2}{*}{$\mathrm{V}$} & Laceration & $\begin{array}{l}\text { Parenchymal disruption involving }>75 \% \text { of hepatic lobe or }>3 \text { Couinaud's segments within } \\
\text { a single lobe }\end{array}$ \\
\hline & Vascular & Juxtahepatic venous injuries (i.e., retrohepatic vena cava/central major hepatic veins) \\
\hline VI & Vascular & Hepatic avulsion \\
\hline
\end{tabular}

\section{Initial approach}

Every trauma victim should be assisted according to the protocol advocated by Advanced Trauma Life Support (ATLS). A sequential primary assessment of the patient's clinical condition should be performed for the priority treatment of injuries involving life-threatening injuries [18-20]. The stages of primary care are evaluation and maintenance of the airways, breathing, ventilation, as well as circulation with hemorrhagic control. It is noted, therefore, that the conduct to be taken will depend on the situation found [19].

Patients with retrograde hepatic IVC lesion present hemodynamic instability and need for volume replacement [15]. A study by Klein et al. demonstrated that more blood pockets were used in retrohepatic injuries when compared to extrahepatic vena cava lesions [17].

Hemodynamic instability, hypothermia, and coagulopathy are consequences of severe bleeding and delayed identification of lesions in the retrohepatic segment. These signs reduce the final efficacy of operative treatment. Thus, early recognition of the injury is essential for acquiring success in the surgical management of patients with excessive volume loss $[20,21]$.

\section{Management of abdominal trauma}

Closed abdominal trauma is a challenge in clinical practice. In the patient who is hemodynamically stable and without lesions in other systems, the physical examination is sufficient for the diagnosis of severe intra-abdominal injury [3-5]. However, it is often not possible to identify if there was an intra-abdominal injury only with the physical examination. In these cases, it is necessary to use complementary tests, such as Peritoneal Diagnostic Washout (PDW), FAST (Focused Assessment Sonography for Trauma), and Computed Tomography (CT) [7-9].

The absolute contraindication for the performance of PDW or FAST is the indication of exploratory laparotomy, pneumoperitoneum, physical examination compatible with peritonitis/peritoneal irritation, penetrating trauma with evisceration, or open abdominal trauma [19-22]. FAST is used in the trauma room and has successfully replaced PDW. It is useful in the initial evaluation of the injury, allowing rapid assessment at the bedside for hemoperitoneum and hemopericardium. It presents the sensitivity of $63-100 \%$ and specificity of $95-100 \%$ for the presence of blood [18, 23].

In hemodynamically unstable patients with PDW or FAST positive, exploratory laparotomy is indicated. In stable, PDW, or FAST positive patients, the next step is to perform a CT scan of Abdomen $[19,24]$. CT allows the detailed assessment 
of lesions of solid and retroperitoneal organs. For hepatic lesions, it has a sensitivity of 92-97\% and specificity of $98.7 \%$. CT contrast extravasation requires emergency angiography and angioembolization in hemodynamically stable patients. The sensitivity and specificity for identification of active bleeding in hepatic lesions is 75\% and 68-93\%, respectively $[18,25]$.

Thus, in patients with peritonitis, exploratory laparotomy is indicated. In patients without signs of peritonitis and hemodynamic instability, laparotomy is shown in the presence of FAST or PDW positive. In laparotomy, if a retroperitoneal hematoma is observed in zone 1 with no other causes of instability, the operation of the hematoma is indicated. If there are other causes of instability, or there are no surgical indications to approach the hematoma; it should not be explored [1, 10-13].

In patients without signs of peritonitis, which have hemodynamic stability, there is an indication of Tomography if PDW or FAST is positive. Once CT was performed, in the presence of pericaval hematoma, only observation ${ }^{26}$. If CT shows other surgical causes, laparotomy is indicated. In hemodynamically stable patients with negative FAST or LPD, there is no need for CT, and only clinical observation is adequate (Figure 4) [21].

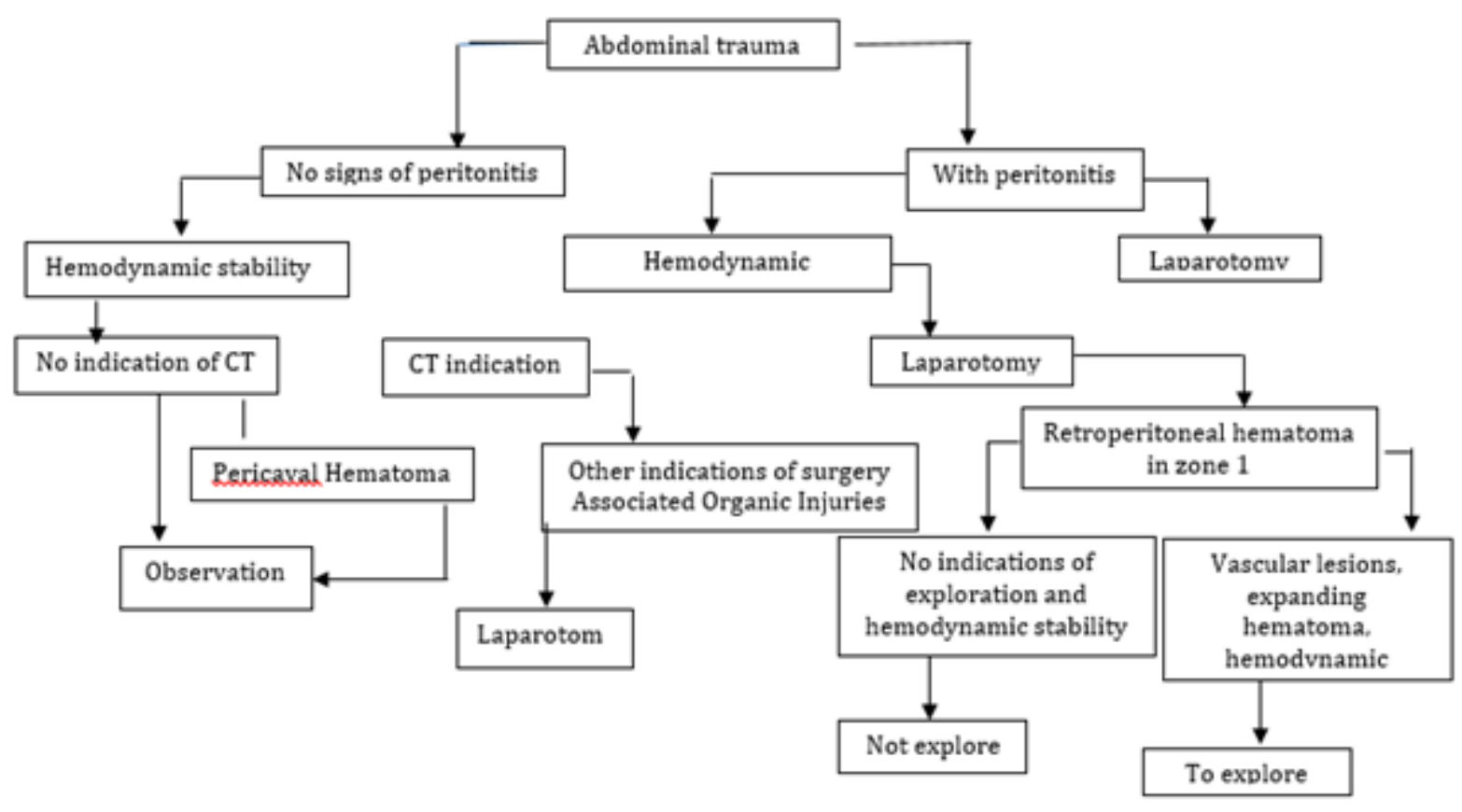

Figure 4 Management of abdominal trauma

\section{Treatment}

\subsection{Injury tamponade / surgical repair}

In the case of retrohepatic IVC lesion, active hemorrhage requires rapid decision and adequate hepatic packaging is an option, with the posterior compression of the liver against IVC, to buffer the lesion; or even using the digital compression technique, through compression of the bleeding point $[22,26]$. If this approach does not control bleeding, the exposure of the retrohepatic IVC will be necessary for the repair of the lesion. In this sense, the source of the injury is identified using the Pringle maneuver, which consists of the temporary occlusion of the portal triad - hepatic artery, common bile duct and portal vein located in the hepatoduodenal ligament [23]. The persistence of bleeding confirms the retrohepatic IVC as a probable source of injury, whereas the reduction of bleeding reveals the hepatic parenchyma as the primary source of hemorrhage [24, 27].

Median laparotomy is not sufficient for adequate visualization of the posterior surface of the liver and retroperitoneum. Thus, after a bleeding exploration decision, laparotomy is associated with a right subcostal incision, and the liver ligaments are sectioned, enlarging the visualization of the retrohepatic IVC. After hemorrhage control, lesion repairs can be performed under direct vision [24]. 
Reports in the literature regarding the use of techniques that aim at a field without blood that facilitate the visualization of the structures to be manipulated ${ }^{17,}{ }^{18}$. One option is the circulatory arrest technique associated with deep hypothermia, used in patients with penetrating hepatic trauma and retrohepatic IVC. This technique is contraindicated in cases of associated lesions and systemic heparinization. During the procedure, a field without blood is allowed to maintain a precise and safe repair in up to $1 \mathrm{~h}[25,28]$.

Another option is the use of extracorporeal circulation, in which blood flow is diverted from the injured area using the extracorporeal circuit, with or without active mechanical pump (Figure 5) [18,24].

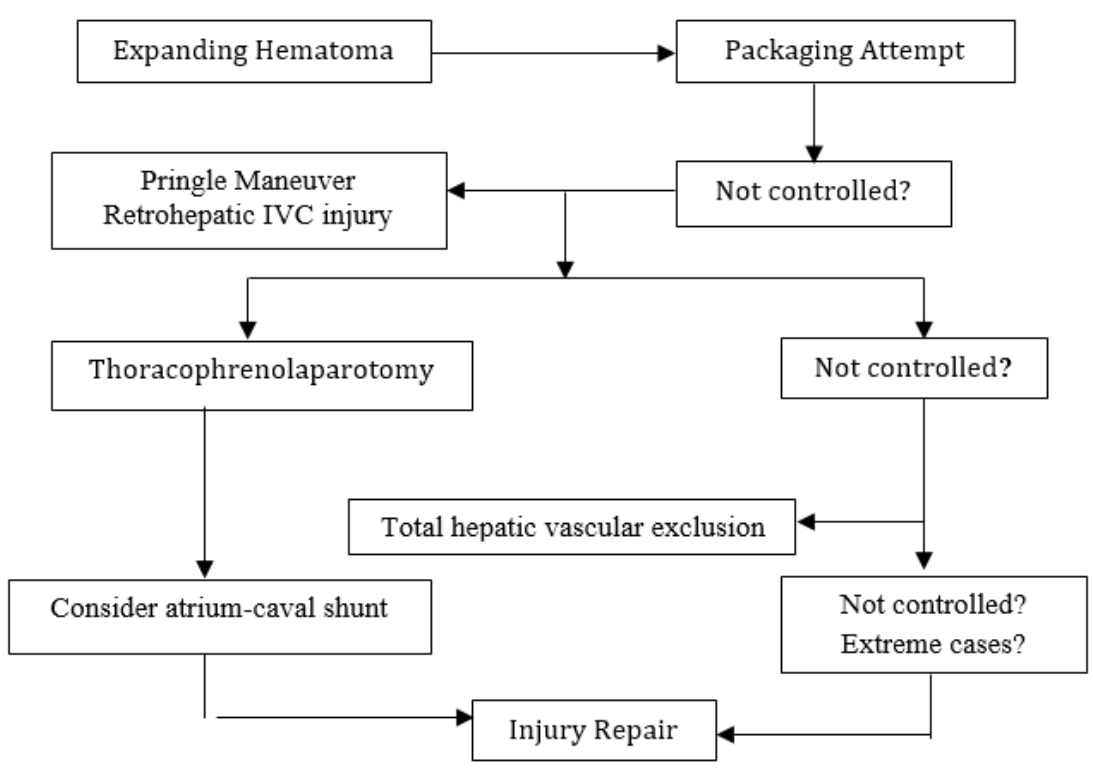

Figure 5 Surgical management of traumatic retrohepatic vena cava injury

\subsection{Total hepatic vascular exclusion}

For lesions that have not been controlled with tamponade, the total hepatic vascular exclusion is the treatment of choice. Procedure consists in performing, in association with the Pringle maneuver, clamping of the IVC above and below the lesion [21-23]. Superiorly, the suprahepatic infra diaphragmatic vena cava is isolated; inferiorly, clamping of the adrenal vena cava occurs. Subsequently, the suprahepatic vena cava is sectioned, and the liver retracted anteriorly to allow a posterior approach to the retrohepatic and retrohepatic vena cava [24, 26].

The use of vascular clamping has the complication of reducing cardiac preload and increasing the risk of arrhythmias by compensatory post-load lifting [17]. Some authors warn that the risk of cardiorespiratory arrest is higher due to the sudden reduction of cardiac preload; however, other authors have not described this outcome (Figure 6) [27-29].

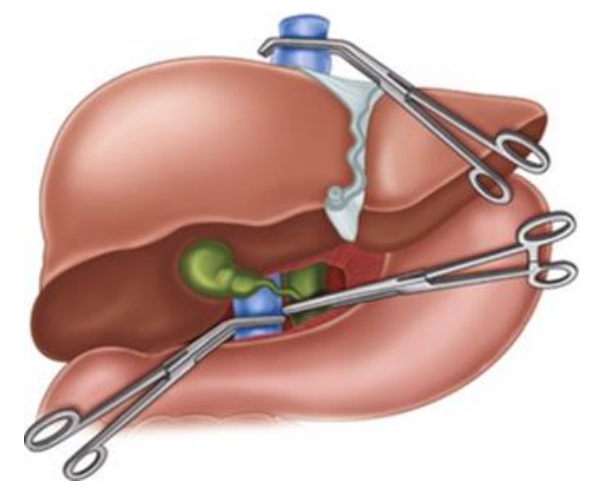

Figure 6 Total hepatic vascular exclusion Source: $\underline{\text { https://link.springer.com/chapter/10.1007/978-1-4939-1200-1 10 }}$ 


\subsection{Shunt atriocaval}

In extreme cases, the atriocaval shunt can be performed, despite high mortality rates, extending the laparotomy to a median sternotomy. The disadvantage of the shunt is related to the technical error, which is challenging to perform, and to the time of the procedure, which is twice as high in comparison with the clamping, besides conferring more significant volume loss [17].

The technique is to perform a bypass by inserting a catheter through the right atriotomy. A lateral orifice is sectioned at the proximal end of the catheter at the level of the right atrium, and the distal end rests just above the renal veins, thus allowing the caval blood to return to the heart. In this way, vascular clamps are positioned around the intrapericardial and adrenal portions of the IVC [30].

The shunt allows sufficient continuous venous return to maintain the ventricular filling pressures required to sustain cardiac output while simultaneously providing a "no-blood" field for repair of the injured vascular structure [23].

Although the use of atriocaval shunt is useful in the management of penetrating hepatic trauma, its use in the hepatic vein or retrohepatic IVC lesions for blunt trauma remained unsuccessful and fatal, with few cases of survivors [29, 30].

The complications of shunt insertion are few but serious. The gas embolism is only one, requiring, therefore, extreme care in the introduction of the catheter. Additional complications include perforation of vascular structures at the insertion, pulmonary embolism, and thrombosis [31].

The technique of vascular isolation showed a better survival rate compared to atriocaval shunt [32]. During operative repair, if the patient develops coagulopathy, acidosis, or hypothermia, the damage control surgery must be considered (Figure 7/A-C) [18, 24].

A

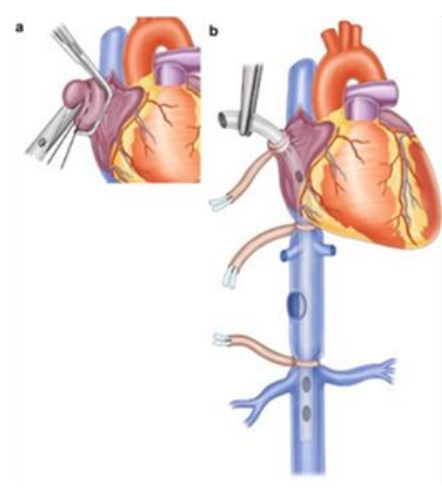

B

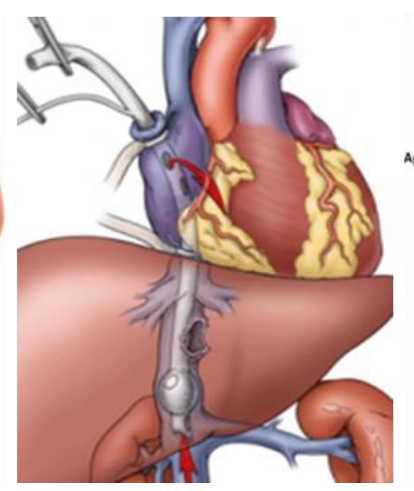

C

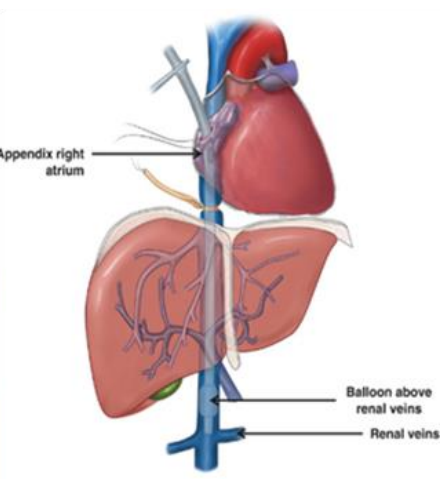

Figure 7A/B -Atrial opening with balloon passage through the inferior vena cava. 7C - Atriocaval shunt functioning after fixation of the tube in the atrium and infrahepatic inferior vena cava with an inflated balloon Source: $\underline{\text { https://link.springer.com/chapter/10.1007/978-1-4939-1200-1 } 10}$

\subsection{Surgical treatment for iatrogenic injuries}

In the context of iatrogenic lesions of retrohepatic IVC, the repair usually requires open surgery at the expense of high morbidity and mortality to the patient. To describe an alternative approach, Briggs et al. reported the sixth case known in the literature of endovascular therapy in a retrohepatic IVC lesion [5]. His report corroborates with the findings of the situations described previously: stent placement in the control of the lesion is effective [5-7].

As potential risks to endovascular device insertion, Erzurum et al. they emphasized erosion of the vena cava, venous rupture, infectious processes, and occlusion [33]. However, due to the scarcity of cases and data in the literature, it is still not possible to estimate the repercussions that these materials could cause in the venous system in the long term, which justifies the need for short-term follow-up and imaging surveillance. Another controversial point is regarding anticoagulation, its indication, and duration in the monitoring of these patients [5, 34]. 


\section{Postoperative complications}

Postoperative complications in patients with retrograde hepatic IVC injury are more frequent than those with lesions in other topographies. Hemorrhages, partial hepatic necrosis, Budd-Chiari syndrome ${ }^{17}$, abdominal compartment syndrome ${ }^{27}$, subphrenic abscesses, hemobilia, and biliary fistulas [34-36].

\section{Conservative treatment}

Although recent, it is possible to infer that it is feasible to perform non-operative treatment in selected cases of traumatic lesions of retrohepatic IVC [4, 37].

There is no doubt about the need for an immediate surgical approach to a patient presenting active bleeding or hemodynamic instability with signs of peritonitis4, given the imminent risk of lethal outcome in these cases $[32,33]$.

However, there is a high mortality rate inherent in performing the operative procedure. Despite the controversies regarding the possibility of subsequent rupture and death in patients not submitted to surgery, it is necessary to consider the decision to be made, individualized for the different types of injury and severity of cases [37].

Therefore, in patients with localized bleeding or the presence of only local hematoma, it is prudent to evaluate the possibility of conservative management through hemodynamic support in an intensive care unit, invasive and radiological monitoring [4-6, 37]. Imaging techniques such as venocavography or duplex ultrasonography should be performed to assess possible complications at the site of injury4. The ideal time for the realization of the images is still uncertain, given the scarcity of information in the literature about the subject [37].

Long-term complications associated with conservative management include stenosis, thrombosis, or pseudoaneurysm in retrohepatic IVC [4].

\section{Conclusion}

In conclusion, there is a high rate of failure inherent in the execution of surgery for the treatment of retrograde hepatic injury of IVC, and, despite the controversies regarding the possibility of subsequent rupture and death in patients not submitted to operative procedure, it is necessary to individualize each case, suggesting the possibility of conservative therapy. Furthermore, given the high mortality rate and the various complications resulting from this lesion, continuous clinical and surgical improvement is necessary for satisfactory outcomes to be obtained more frequently.

\section{Compliance with ethical standards}

\section{Acknowledgments}

The authors thank Prof. Dr. Aldo Medeiros, Full Professor of the Department of Surgery - UFRN, for the supervision of this review, acting as an expert consultant on the bibliographic survey, analysis, and scientific advice. We also thank all the study components for their dedication and effort to build a scientifically validated quality review.

\section{Disclosure of conflict of interest}

There are no conflicts of interest to declare by any of the authors of this study.

\section{References}

[1] Kashuk JL, Moore EE, Millikan JS and Moore JB. (1982). Major abdominal vascular trauma a unified approach. J Trauma, 22(8), 672-679.

[2] Sullivan PS, Dente CJ, Patel S, Carmichael M, Srinivasan JK, Wyrzykowski AD, Nicholas JM, Salomone JP, Ingram WL, Vercruysse GA, Rozycki GS and Feliciano DV. (2010). Outcome of ligation of the inferior vena cava in the modern era. Am J Surg, 199(4), 500-506.

[3] Millikan JS, Moore EE, Cogbill TH and Kashuk JL. (1983). Inferior vena cava injuries - A continuing challenge. J Trauma, 23(3), 207-212. 
[4] Khan IR, Hamidian Jahromi A, Khan FM and Youssef AM. (2012) Nonoperative management of contained retrohepatic caval injury. Ann Vasc Surg, 26(3), 420, 9-12.

[5] Briggs CS, Morcos OC, Moreira CC and Gupta N. (2014) Endovascular treatment of iatrogenic injury to the retrohepatic inferior vena cava. Ann Vasc Surg, 28(7), 1794, 13-5.

[6] Cogbill TH, Moore EE, Jurkovich GJ, Feliciano DV, Morris JA and Mucha P. (1988). Severe hepatic trauma: a multicenter experience with 1335 liver injuries. J Trauma, 28(10), 1433-1438.

[7] Maciel JD, Plurad D, Gifford E, deVirgilio C, Koopmann M, Neville A, Putnam B and Kim DY. (2015). predictors of mortality in patients with penetrating inferior vena cava injuries surviving to the operating room. Am Surg, 81(10), 1000-1004.

[8] Huerta S, Bui TD, Nguyen TH, Banimahd FN, Porral D and Dolich MO. (2006). Predictors of mortality and management of patients with traumatic inferior vena cava injuries. Am Surg, 72(4), 290-296.

[9] Buckman RF, Pathak AS, Badellino MM and Bradley KM. (2001). Injuries of the inferior vena cava. Surg Clin North Am, 81(6), 1431-1447.

[10] Zheng W, Zi-hai D, Jie Z, Shi-zhen Z, Jian-hua L and Yi-xiong L. (2017). Anatomy of the retrohepatic tunnel in a Chinese population and its clinical application in liver surgery. Scientific Reports, 21(7), 44977.

[11] Tenório NJ, Goldenberg A and Triviño T. (2002). A exposição do contorno lateral direito da veia cava inferior na cirurgia hepática. Acta Cir Bras, 17(2), 95-101.

[12] Rosengart MR, Smith DR, Melton SM, May AK, Rue LW 3rd. (1999). Prognostic factors in patients with inferior vena cava injuries. Am Surg, 65(9), 849-856.

[13] Ombrellaro MP, Freeman MB, Stevens SL, Diamond DL and Goldman MH. (1997). Predictors of survival after inferior vena cava injuries. Am Surg, 63(2), 178-83.

[14] Netto FA, Tien H, Hamilton P, Rizoli S, Chu P, Maggisano R, Brenneman F and Tremblay LN. (2006). Diagnosis and outcome of blunt caval injuries in the modern trauma center. J Trauma, 61(5), 1053-1057.

[15] Hansen CJ, Bernadas C, West MA, Ney AL, Muehlstedt S, Cohen M and Rodriguez JL. (2000). Abdominal vena caval injuries: outcomes remain dismal. Surgery, 128(4), 572-578.

[16] Clark JJ, Steinemann S and Lau JM. (2010). Use of an atriocaval shunt in a trauma patient: First reported case in Hawai'i. Hawaii Med J, 69(2), 47-48.

[17] Klein SR, Baumgartner FJ and Bongard FS. (1994) Contemporary management strategy for major inferior vena caval injuries. J Trauma, 37(1), 35-41.

[18] Ahmed N and Vernick JJ. (2011). Management of liver trauma in adults. J Emerg Trauma Shock, 4(1), 114-119.

[19] American College of Surgeons Committee on Trauma. Advanced Trauma Life Support (ATLS) Student Course Manual, 10 ${ }^{\text {th }}$ ed, American College of Surgeons, Chicago 2018.

[20] Beal SL and Ward RE. (1989). Successful Atrial Caval Shunting in the Management of Retrohepatic Venous Injuries. Am J Surg, 158(5), 409-413.

[21] Van Rooyen PL, Karusseit VO and Mokoena T. (2015). Inferior vena cava injuries: A case series and review of the South African experience. Injury, 46(1), 71-75.

[22] Ai-Jun L, Meng-Chao W, Guang-shun Y, Han C and Fen S. (2004). Management of retrohepatic inferior vena cava injury during hepatectomy for neoplasms. World J Surg, 28(1), 19-22.

[23] Pringle JH. (1908).Notes on the arrest of hepatic hemorrhage due to trauma. Ann Surg, 48, 541-549.

[24] Bardes JM, Grabo D, Lam L, Tadlock MD, Strumwasser A and Inaba K. (2017). Treatment algorithm and management of retrohepatic vena cava injuries. J Trauma Acute Care Surg, 83(2), 340-344.

[25] Hartman AR, Yunis J, Frei LW and Pinard BE. (1991).Profound hypothermic circulatory arrest for the management of a penetrating retrohepatic venous injury: case report. J Trauma, 31(9), 1310-1311.

[26] Buechter KJ, Gomez GA and Zeppa R. (1990). A new technique for exposure of injuries in the confluence of the retrohepatic veins and the retrohepatic vena cava. J Trauma, 30(3), 328-331. 
[27] Rogers FB, Reese J, Shackford SR and Osler TM. (1997). The use of venovenous bypass and total vascular isolation of the liver in the surgical management of juxtahepatic venous injuries in blunt hepatic trauma. J. Trauma, 43(3), $530-533$.

[28] Weber S, Murphy MM, Pitzer ME and Davis K Jr. (1996). Management of retrohepatic venous injuries with atrial caval shunts. AORN J, 64(3), 376-382.

[29] Yellin AE, Chaffee CB and Donovan AJ. (1971). Vascular isolation in treatment of juxtahepatic venous injuries. Arch Surg, 102(6), 566-573.

[30] Depinto DJ, Mucha SJ and Powers PC. (1976). Major hepatic vein ligation necessitated by blunt abdominal trauma. Ann Surg, 183(3), 243-246.

[31] Bricker DL, Morton JR, Okiec JE and Beal AC Jr. (1971). Surgical management of injuries to the vena cava: changing patterns of injury and newer techniques of repair. J Trauma, 11(9), 725-735.

[32] Yilmaz TH, Ndofor BC, Smith MD and Degiannis E. (2010). A heuristic approach and heretic view on the technical issues and pitfalls in the management of penetrating abdominal injuries. Scand J Trauma Resusc Emerg Med, $14(18), 40$.

[33] Erzurum VZ, Shoup M, Borge M, Kalman PG, Rodriguez H and Silver GM. (2003). Inferior vena cava endograft to control surgically inaccessible hemorrhage. J Vasc Surg, 38(6), 1437-1439.

[34] Pachter HL, Spencer FC, Hofstetter SR, Liang HG and Coppa GF. (1992). Significant trends in the treatment of hepatic trauma. Experience with 411 injuries. Ann Surg, 215(5), 492-500.

[35] Baumgartner F, Scudamore C, Nair C, Karusseit O and Hemming A. (1995). Venovenous bypass for major hepatic and caval trauma. J. Trauma, 39(4), 671-673.

[36] Gao JM, Du DY, Zhao XJ, Liu GL, Yang J, Zhao SH and Lin X. (2003). Liver Trauma: Experience in 348 Cases. World J Surg, 27(6), 703-708.

[37] McGreevy CM, Anjaria DJ and Kunac A. (2016). Nonoperative management of a penetrating injury to the retrohepatic inferior vena cava. Am Surg, 82(8), 212-213.

\section{How to cite this article}

Melo e Silva BB, Dantas EA, Arboés HER, Oliveira LQ, Veras de Freitas MA, Rêgo ACM and Araújo-Filho I. (2019). Retrohepatic vena cava lesion: which we cannot forget? World Journal of Advanced Research and Reviews, 3(1), 01-11. 